\title{
Transformation and Upgrading of Manufacturing Service-Taking ShaanGu as an Example
}

\author{
Zhao Wu, Liu Wei \\ School of Economics and Management, Xidian University, Xi'an, China \\ Email: zhsxwu@xidian.edu.cn,1733787629@qq.com
}

How to cite this paper: $\mathrm{Wu}, \mathrm{Z}$. and Wei, L. (2018) Transformation and Upgrading of Manufacturing Service-Taking ShaanGu as an Example. Open Journal of Business and Management, 6, 47-59.

https://doi.org/10.4236/ojbm.2018.61004

Received: October 26, 2017

Accepted: December 29, 2017

Published: January 3, 2018

Copyright ( $\odot 2018$ by authors and Scientific Research Publishing Inc. This work is licensed under the Creative Commons Attribution International License (CC BY 4.0).

http://creativecommons.org/licenses/by/4.0/

Open Access

\begin{abstract}
The rapid rise of the service economy has led to significant changes in the industrial structure. Instead of taking a single reliance on product for development, manufacturing should develop service-oriented manufacturing because it offers opportunities for innovation and development for the Chinese manufacturing industry. This paper analyzes the important stage of the development of ShaanGu and discusses the core measures of supporting the ShaanGu in the manufacturing industry. At the same time, in the face of the depression of the current manufacturing market, this is manufacturing enterprises to transform and upgrade to provide guidance for service-oriented manufacturing recommendations.
\end{abstract}

Keywords

Service-Oriented Manufacturing, ShaanGu, Case Study

\section{Introduction}

With the development of global economy and the change of customer consumption concept, more and more manufacturing enterprises will be bundled with products and services in the form of profit. Business manufacturing and service business between the boundaries become increasingly blurred. In the United States, there are nearly $60 \%$ of the manufacturing enterprises to achieve the products and services bundled. However, China has $97.8 \%$ of the manufacturing enterprises are still implementing a product-led strategy, which can not effectively participate in international market competition.

Traditional manufacturing companies based on its market positioning, focus- 
ing on physical products, technological innovation, quality improvement and cost reduction and other operational strategies improve production efficiency, and then win the competitive advantage. However, with the advent of the service economy, manufacturing companies rely solely on the traditional operational strategies that have been stretched and need to shift the focus of the business from pure manufacturing to manufacturing and service (Lay et al., 2010). Products as a carrier, through product-related services to enhance the value of the product, has been considered as an indispensable element of the current research and development of manufacturing enterprises. As Premier Li Keqiang at the Beijing Summit Global Service Forum at the Second Beijing Trade Fair, "Developed economies, while seeking to reindustrialize and remanufacture, are striving to maintain the leading position in the service industry. In the process of promoting industrialization in developing countries, trying hard to make up for the shortfall in service industry" (Li Keqiang, 2013). Under this background, how to promote the transformation and upgrading of manufacturing enterprises through service has become the focus of current research.

\section{Servitization in Detail}

The range of services that can be offered by manufacturing firms is quite large. It spans from delivery services to leasing, customization of the product, installation, maintenance, updates, and financing facilitation. Ren and Gregory (2007) [1] pointed out that service is a process of change, manufacturing companies gradually accept the service-oriented, or to develop more and better services for the purpose of meeting customer needs, to achieve business competitive advantage and improve business profit. The servitization can also enable firms to differentiate their products from those of their competitors (Gebauer, Gustafsson, \& Witell, 2011) [2], increase customer loyalty (Baines \& Lightfoot, 2013) [3], and increase market values (Fang et al., 2008) [4] or increase profitability (Suarez, Cusumano, and Kahl, 2013 [5]; Visnjic, Wiengarten, \& Neely, 2016) [6]. Baines and others through the study of the British manufacturing industry found that the use of service strategy manufacturing enterprises can be more access to user recognition, and effectively increase revenue and reduce organizational change costs.

US economist Greenfield in the study of service industry and its classification, for the first time put forward the concept of producer services (producer Services), the theoretical content of the market refers mainly to the middle of the service, that is, the production process. The most prominent feature of the service industry is that it provides the non-terminal consumption service such as scientific research and development, engineering design and marketing. It is a kind of supporting service industry which exists in the manufacturing enterprise. Sun Linyan (2007) [7] for the first time formally put forward the concept of service-oriented manufacturing, its theoretical content is relying on products will be productive services, service production and customer participation in the in- 
troduction of traditional manufacturing value chain, expand its coverage, through the enterprise Professional division of labor and collaboration, to achieve resource integration, value appreciation and knowledge innovation goals, enhance the core competitiveness of manufacturing enterprises; Hezhe et al. (2008) [8] compared the supply chain differences between service-oriented manufacturing and traditional manufacturing, and considered that service-oriented manufacturing was a manufacturing system from $\mathrm{R} \& \mathrm{D}$, production to after-sales and remanufacturing; Lin Wenjin et al. (2009) [9] will be defined as a service-oriented manufacturing through a network of collaboration to achieve the development of services and services to the manufacturing penetration, and ultimately to provide customers with "product service system", so that enterprises in creating value for customers The same time to obtain their own interests in the manufacturing model. The above research makes a thorough analysis of the core concepts of service-oriented manufacturing, and establishes the theoretical basis of service-oriented manufacturing research.

\section{Case Study of ShaanGu}

\subsection{Basic Situation of Shaan Gu}

Shaan Gu was founded in 1968 as a manufacturer and supplier of mechanical system solutions and system services for pillar industries such as metallurgy, petroleum, chemical industry, electric power, air separation, urban construction, environmental protection, pharmaceutical and national defense. And service providers, ShaanGu traditional products include axial flow compressor, industrial process energy recovery turbine device, centrifugal compressor, centrifugal blower, large fan, steam turbine a total of six categories 80 series of more than 2000 varieties specifications. In recent years, with the reorganization of the company, ShaanGu products include the ShaanGu power, ShaanGu spare parts, ShaanGu West instrument, ShaanGu West pot, ShaanGu industry and ShaanGu water six subsidiaries, and ShaanGu energy power and automation Engineering Research Institute. ShaanGus rely on the traditional manufacturing business service innovation and the successful realization of a single product suppliers to set design, manufacturing, engineering total package, installation, maintenance, maintenance and upgrading as one of the power of complete sets of equipment system solutions and system service providers The strategic transformation, the formation of the energy conversion equipment Equipment manufacturing, energy conversion system services and energy infrastructure operations of the three plates of the business, effectively enhance the comprehensive competitiveness of enterprises in ShaanGu. From 2001 to 2012, the scale of enterprises increased from 337 million yuan to 6.901 billion yuan and total operating income increased from 3.12 billion yuan to 6.042 billion yuan. Since 2005, more than $60 \%$ of the gross output value of ShaanGu's has come from the innovation of "technology + management + service" management mode. 


\subsection{Transformation Factor}

Through data collation and field interviews, Shaoguan implemented serviceoriented manufacturing drivers including three aspects:

Firstly, the manufacturing environment has changed dramatically. The degree of economic globalization is deepening day by day, and customer needs are further complicated and dynamic. At the same time, the proportion of manufacturing industry in the national economy is shrinking day by day. The outbreak of the financial crisis and fierce price competition have forced manufacturing enterprises to jump out of the traditional business model and open up new development path. Therefore, since the second half of the 20th century, the service industry in the world has been rapidly developing, and the value-added part of the service economy of various countries has been expanding steadily as a share of the gross national product.

Secondly, the transformation is the need of Shagu drum itself. As early as the early 21st century, Shaanxi drum has become the world's largest manufacturer of axial compressors. However, the Shaanxi and Drum realized that there will always be "ceiling" in market demand. If the enterprise still follows the traditional mode of manufacturing development, it will be hard to get rid of the low-profit "Red Sea" situation. In the event of an economic crisis and the fall in demand and it will bring tremendous damage. More importantly, Shaan Kwu already possesses the fundamental support for the transformation, that is, the core technology for producing all kinds of advanced equipment. Because enterprises are aware that the transformation must be based on core technologies and core products, and if there is no key core technology, the transformation must encounter numerous difficulties. Therefore, Shagu Kwu has never given up its core business in its own development process and continuously conducted research and development on new products and technologies.

Finally, the use of advanced technology is a key factor in the successful transformation. It is through the introduction of the Shaanxi Drum Drum a series of advanced technologies and measures such as the Internet, Internet of things, cloud computing, remote service control, making the service possible. The establishment of Shaanxi Drum Rotary Machinery Remote On-line Monitoring and Fault Diagnosis Center marks that Shaanxi drums have reached a new stage in the process of service. At this center, Shaan-kuang can monitor all its running equipment in real-time so as to continuously obtain the operating parameters of the equipment and analyze the data through the connection with the expert system so as to grasp the operation status of the equipment in time, The emergence of the fault warning. For Shaan-kuang, analysis of the data can make it more scientific to improve the product, so that the performance of the product is more excellent; for customers, the introduction of equipment failure warning function to minimize the sudden interruption of production to ensure that The continuity of production. 


\subsection{A Brief Analysis of the Transformation of ShaanGu}

China's gradual entry into the post-industrial era, the traditional manufacturing enterprises trapped in the homogenization of competition and price war difficult to extricate themselves, at the same time, the customer's consumer demand from a single product to the system solution changes and companies want to meet customer needs, Out of the product of the trap, it must be a new modern enterprise management ideas and development ideas-service-oriented manufacturing to examine their own development; the other traditional market demand close to saturation, market demand into the "ceiling" era, large equipment companies Excess capacity of the situation, if you can not expand the market demand, companies will face a serious crisis of survival. Although the construction of the drums since the continuous profitability, but a single product type and backward management mechanism allows enterprises to simply maintain the "safe food" state, as of the end of 2000, ShaanGu industrial value is only 340 million yuan, profits 840 Million, at the time of the market competition and not much advantage. ShaanGus in order to achieve the core competitiveness of enterprises to enhance their own development model must be a thorough change.

\subsubsection{Transforming Enterprise Development Ideas-From Product Orientation to Service Orientation}

The idea of restraint is always the yoke of the transformation of enterprises. But once out of the traditional development of the old manufacturing industry, enterprises will usher in a different kind of spring. As early as 1999, India Jianan in a coincidence to see a set of IBM developed by the remote customer support service system. This system gave the Indian Jianan great touch, combined with the mechanical industry after-sales service development lag, he soon initiation of the establishment of a remote control system to judge and provide customers with timely maintenance program ideas. In 2001, Chairman,which is Yinjianan, took over the work of ShaanGu, he began to try to a new modern business philosophy and development ideas to examine the traditional drum manufacturing industry, the direction of development, and more than a dozen China led the drum group gradually out of the traditional manufacturing development of the old road, embarked on the "from manufacturing, beyond manufacturing" new road of industrial development, so that drum marketing model by the blower, fan and other sales into gas Sales, created by the sales change to the service of innovation.

\subsubsection{Based on Professional Services-To Provide Professional Maintenance Services}

The maintenance service market is a lucrative, and at the most high end of the added value of the smiling curve, known as "never sinking an aircraft carrier". With the professional division of labor more and more fine, the customer originally set up the maintenance team can not meet their own development needs. On the one hand, maintenance and very much, resulting in waste of human resources, on the other hand, the real need for maintenance and because of professional knowledge and experience constraints can not be completed. Equipment 
manufacturers focus on a large number of professional elite, and there are many professional maintenance services, customer service can be repaired.

1) Low-end maintenance service outsourcing. From 2005 onwards, Shaan Gu will be part of the equipment maintenance projects (including on-site management, maintenance, accessories and lubrication) contracted to Beijing, such as Technology Co., Ltd. For example: the supply of machinery, electrical and hydraulic spare parts for all equipment (imported spare parts, spare parts for domestic OEMs); contracted all equipment for daily oil supply, cleaning oil change and equipment platform leakage work and so on. ShaanGu group maintenance center management equipment workshop, workshop maintenance, spare parts library, oil depots from Beijing, such as contractors, ShaanGu group and Beijing, such as cooperation, the entire equipment management and maintenance center personnel into the product after-sales service, while promoting the ShaanGu Remote On-line Monitoring and Fault Diagnosis Application and Development.

2) To do high-end professional maintenance value-added services. 2001-2004, ShaanGu has completed the Tianjin steel pipe steam turbine, mixed flow compressor (Germany GHH), Zhangjiagang Hongfa axial compressor (Switzerland Sulzer) and other projects maintenance, maintenance, and accumulated a lot of valuable experience. In recent years, ShaanGu repair service and onto a new level. In July 2013, ShaanGu has set up a service center in Tangshan to realize the "on-site service" covering the Beijing, Tianjin, Tang and Hebei users, which will further develop the advantages of regional and localized services, shorten the service cycle, Project implementation quality and efficiency, on-site treatment of various types of problems, to help users correct use and maintenance of equipment to reduce the number of downtime; at the same time through the establishment of spare parts library, in a short period of time can provide users with genuine original spare parts, Time will be reduced by more than $20 \%$ over time.

Professional maintenance services to achieve the drums and customers win-win situation. First of all, in terms of customers, customers do not need long-term employment of professional maintenance team, reducing labor costs. At the same time, Shaan $\mathrm{Gu}$ repair team of high degree of specialization, experience, maintenance speed, improve the efficiency of equipment maintenance, reducing the huge losses caused by the failure. Second, in terms of drums, its professional maintenance services to meet customer needs and improve customer satisfaction, increase customer stickiness, to achieve a substantial increase in market space, and access to maintenance profits. So as to truly achieve a new situation of mutual benefit and win-win situation.

\subsubsection{Internet-Based Services-Provision of Equipment for Remote Diagnosis Services for Customers}

Shaan Gu large-scale equipment technology is more complex, and more for the customer's production process on the core of key equipment, the need for higher reliability; with more parts, any component in the event of a problem, will likely 
cause the overall system downtime, If the parts can not be completely damaged before the timely detection, you can avoid downtime on the production impact. To this end, in 2002, ShaanGu and Xi'an Jiaotong University and Shenzhen, a real technology Development Co., Ltd. cooperation, the information technology and traditional industrial model of the organic combination of research and development of the first domestic INTERNET remote management based on the rotation Mechanical remote online monitoring and fault diagnosis center. Based on this system, ShaanGu can carry out all-weather, whole process, all-round state management of customer's equipment, and the technical data of the client unit running through the Internet is continuously input into the remote monitoring and fault diagnosis center database of ShaanGu. This service system has three functions: real-time monitoring of the operation of the equipment during the operation of the state, to provide customers with monthly diagnosis, special failure analysis, emergency troubleshooting and special status of the operation of the proposed report to facilitate customer service equipment, spare parts Replacement of the decision-making; to help solve the scene staff in the equipment debugging, testing, maintenance problems in the process; through finishing the real-time detection of different equipment operating status, the same type of equipment exist multiple fault design, manufacturing aspects of the mechanism Research to improve the quality of the product. At present, the drum has been nearly 60 users of the country more than 200 sets of products to provide remote detection services. ShaanGu also for the user to establish health management files, the use of remote monitoring technology on a regular basis for user equipment diagnostic analysis to predict the future operation of the unit, and issued a report on the operation of the report, the normal operation of the user equipment escort.

\subsubsection{Based on the Convenience of the Management Services-To Provide Spare Parts for the Management of Spare Parts}

Due to the high degree of specialization provided by the drums in China, in order to avoid the downtime caused by the defective parts, it is necessary for the customers to reserve some fragile parts as spare parts and be able to replace them in time. Customer companies have brought the capital occupied, lack of reserves, custody trouble and other issues. To seize the customer demand for spare parts, ShaanGu to provide spare parts for the management services. From the customer point of view, can effectively solve these three problems. Customers use drums to provide equipment is no longer in advance procurement reserves, but by the ShaanGu is responsible for reserves. Once the crew has problems, these spare parts can be supplied immediately. For customers, one is not necessary to spend money; but do not have to worry about the reserve for some kind of accessories and emergency needs; third is to reduce the storage costs. For the drums, the system can be provided to many customers, because the product of a high degree of serialization, the difference is not large parts, especially the embryo is almost no difference, only a small amount of reserves can be, even if 
the individual spare parts to prepare, You can also use the remote monitoring and diagnostic information to prepare in advance, once the customer needs, you can immediately from the spare parts library can be used directly or a small amount of processing can be used to spare parts, advance delivery or emergency air to the customer site.

Bulky heavy industry is moving towards light capitalization. In the field of non-core business, equipment and services as much as possible to take outsourcing. ShaanGu not only for customers to provide spare parts management services, but also rental spare parts. The same spare part of the drum reserve can be rented to different customers, get the rent and management fees, the original first to sell spare parts of a way of income into multiple gains. This will not only allow customers to save one-time capital investment, more likely to focus on the owners; also let the drum from the transaction into a service-oriented enterprises, several times the growth curve.

Since the provision of spare parts service, drums in 2002-2004 cumulative book price of 124 million yuan, an average annual growth rate of $45 \%$.

\subsubsection{Focus on the Core Product of the Basic Services-Product Lifecycle Services}

The so-called full life cycle management, refers to the enterprise from the product needs, planning, design, production, distribution, operation, use, maintenance until remanufacturing continued to provide services to customers. Customer demand-oriented makes the drum in its service process has always insisted on the customer responsible attitude, so customers are most concerned about the core products, the drums to actively develop the product's full life cycle management, from the product design, production, After-sales, and then manufacturing and other aspects of the level of continuous improvement of their own services, change the passive service for the active service. In the design, the implementation of leading products "zero defect" project, increased product testing and iterative aspects of capital investment, excellence, to ensure no risk at all.

Research and development of the first domestic remote management based on the INTERNET remote monitoring machine remote monitoring and fault diagnosis center, the customer's device can be implemented all-weather, the whole process, all-round state management, the client unit running technical data through the Internet continuously Input to the remote monitoring and fault diagnosis center database of ShaanGu, technical experts can provide online technical support and fault analysis service for 24 hours. Remanufacturing is a service that extends the product life cycle, an industry that implements high-tech remediation and transformation of used products. It is for the damaged or will be scrapped parts and performance failure analysis, life assessment and other analysis on the basis of remanufacturing engineering design.

\subsubsection{Product-Based Derivative Services-Financing Services}

In the face of some customers want to introduce this device is subject to the re- 
cent shortage of funds confused, or individual customers long-term arrears of the phenomenon, ShaanGu combined with the financing needs of customers began to explore a kind of industrial resources and financial resources system integration path, put forward the "financial enterprise + core enterprise + customer enterprise" trinity financing service model, hoping to form a win-win cooperation mode and operation mechanism. According to the individual needs of customers in the capital, the introduction of financial leasing and other $13 \mathrm{fi}$ nancing service model, respectively, "financial institutions part of the financing", "prepayment + installment + accounts receivable factoring" financing, "deposit + ShaanGu + financial institutions financing", "ShaanGu + supporting enterprises + entrusted loans", online credit (Financing - financing), BOT (construction - operation - transfer) financing, specialized joint venture financing, seller's credit buyer's interest payment financing. In recent years, ShaanGu total of 10 customers 14 projects to provide financing services, driven by the order amount of 1.016 billion yuan. 2013, ShaanGu investment income for the first time exceeded 293 million yuan, accounting for the proportion of total corporate profits more than 1/4. At that time, Kunming Iron and Steel companies want to introduce the drums of the TRT device but suffer from financial constraints have been unable to carry out, this ShaanGu in the full market research on the basis of its first to provide TRT device, run and then recycling costs, and ultimately this Project for the drums brought nearly a million financing services income. With the first successful experience, ShaanGu has started to develop the financing services of enterprises. Under the financial support of CITIC Industrial Bank, ShaanGu has provided 120 million yuan of financial services for R \& D steel company TRT project in 2005. In 2013, the investment income of ShaanGu exceeded 293 million yuan for the first time, accounting for more than $1 / 4$ of the total profit of the enterprise. In 2006 ShaanGu contracted 270,000 tons/year dilute nitric acid production plant project general contract orders with Henan Jin Kai Chemical Co., Ltd., a total of 145 million yuan of the total contract. ShaanGu sales creates a single contract the largest amount the record in the history of.

The advantages of financing innovation in ShaanGu is: in terms of ShaanGu, this initiative has expanded its product market and enhanced the competitiveness of enterprises. For financial enterprises, it has expanded the scope of financial and financial products, Aspects of business innovation; on the user business, it broke through the original funding bottlenecks, to ensure the smooth progress of the latter part of the project. ShaanGu financing service innovation achieves a win-win.

\subsubsection{Based on One-Stop Service-To Provide Engineering Services for Customers}

Global manufacturing industry competition is undergoing profound changes in the form of change, the customer needs is no longer a single function of the product, but based on a series of product integration, Is a product that can create value for customers. ShaanGu service innovation in this area is to provide cus- 
tomers with complete sets of services.

As the manufacturing industry is undergoing profound changes, products that replace a single function based on the integration of a range of products become customer needs. General contracting, life cycle service and so on to become the direction of manufacturing development. ShaanGu to provide customers with complete sets of products based on turnkey projects, that is responsible for complete sets of equipment (system design, system equipment, system installation and commissioning) and engineering contracting (including infrastructure, plant, peripheral facilities) and so on. In addition, the drums also provide customers with complete problem-solving solutions for the conditional customers to provide financial financing services, and truly build the service brand of ShaanGu.

With the changing needs of customers, ShannGu simply provide the profit margins of the blower products is increasingly small, as a result of providing a wide range of single business and providing products has become a simple labor. In the vicious competition, profit margins are very small. To this end, ShaanGu by strengthening the allocation of resources, the use of modern scientific and technological means, to expand the scope of services and extension, to provide customers with complete sets of services and engineering contracting services. For example, in 2002, Baosteel Group on the steel plant TRT project tender, ShaanGu provided TRT complete sets of construction projects. This project also allows the drums to harvest a huge profit, if only sell a single product, ShaanGu can only get 6.83 million yuan TRT host orders, but the complete set of projects so that orders from 6.83 million yuan directly into the 30.8 million Yuan, all of a sudden the market expanded nearly five times. After the implementation of complete sets of system services, ShaanGu contract increased by 3.5 times, profits increased by 2.7 times. At the same time, ShaanGu integrated social resources, to provide customers with a complete solution to the problem, the scope of supply expanded, enhanced system management capabilities. Which can compete with the drums of enterprises to greatly reduce the capacity of ShaanGu to obtain orders to be greatly enhanced.

\section{Suggestion}

On the basis of the theory of service-oriented manufacturing industry, this paper analyzes the successful transformation of service-oriented manufacturing ofShaanGu Group, summarizes and summarizes the problems of ShaanGu's business model, business process, production organization and mode of operation change. According to the case of ShaanGu, this article draws the following inspiration:

First, establish awareness and upgrade their service technology. Enterprises in order to achieve the transformation of service-oriented manufacturing, service concept must be transformed into a pilot. First, companies need to do is to guide staff to re-understand the relationship between products and services: clear in 
today's market competition, the prerequisite for the success of core technology knowledge products, in order to remain invincible in the market competition also need to customers Provide valuable personalized service, the formation of "product + service" system solutions. Enterprises can improve the overall quality of service personnel through training and corporate culture, and push the service quality of enterprises to a new high point. Secondly, the promotion of service awareness should be top-down, and superiors should take the lead in their own efforts The role of the model, from top to bottom to promote service awareness, establish a standardized service awareness, to truly carry out service innovation to improve awareness; the last clear job requirements and quality service objectives is also an important measure to improve service quality enterprises will be Quality of service linked to the performance appraisal of employees helps employees to better serve their customers. The quantification and refinement of working standards help us to recognize every aspect of our work that needs improvement. This will also help to improve the quality of service.

Second, customer demand-oriented, the development of personalized customized services. With the development of economy and society, the product choices unidirectionally provided by enterprises can no longer meet the diversified consumer demand of consumers, and the market has begun to enter an era of personalized customization to meet the needs of consumers. Manufacturing enterprises in order to gain competitive advantage in the market competition, we must focus on consumer demand, the development of personalized customized services. As we all know, large-scale standardized production can improve the production efficiency of the product and reduce the production cost of the product. The reason why the production can be standardized is that the enterprise virtually erases the individual differences in the production process of the product. This is in line with the personalized There is a natural contradiction between customization. Therefore, enterprises want to seize the consumer market in the case of ensuring their own profit margins must develop mass customization. Adding customer attributes by adding product attributes is the conversion of a customized product's production problems into a mass production issue through product reorganization and process reorganization.

Third, online support services and product life cycle management should be developed. Traditional manufacturing enterprises in the process of transition to service-oriented manufacturing enterprises, to achieve from the "one-time service" to provide "full life-cycle service" change, full life-cycle service not only extends the enterprise's value creation period, making the production of enterprises The service moves across the higher value-added smile curve, and the company continues to receive customer feedback in the process, providing direction for product and service system improvements. Therefore, enterprises should focus on providing continuous product services to customers through various channels and ways, such as online support services and other interactive activities, to provide customers with information and technical support, timely and effective solution to customer problems in the use of the product, Good 
customer relationship management, maintaining a stable customer relationship.

Fourth, through the use of Internet platform, actively develop the network of precision marketing. In the rapid development of Internet technology today, online marketing has gradually evolved into an important means of marketing. Therefore, manufacturing enterprises want to transition to service-oriented manufacturing enterprises, rapid establishment of personalized customer service system, with the lowest marketing costs, access to maximize the marketing effect, we must develop the network of precision marketing. For this, companies should first conduct an in-depth investigation and analysis of existing consumer markets to understand key audiences and their consumer needs. On this basis, enterprises should be subdivided into existing consumer markets to ensure effective market, product and brand positioning.

Fifth, to provide extension services based on customer actions and develop financial leasing services. Financial leasing has played the role of financial lever in accelerating the transformation and innovation of the manufacturing profitability model and promoting the upgrading of enterprises' technology. Under the current background of transformation and upgrading in China, traditional manufacturing enterprises should pay attention to the development of financial leasing services in the transition to service-oriented manufacturing enterprises. Large enterprises should make use of their own resources to actively establish strategic cooperative relations with relevant financial institutions, To provide financial services such as extending customer service, change passive service as an active service.

Sixth, industrial chain should be integrate to enhance the added value of enterprises. Today's business competition has shifted from competition among enterprises to competition among industries. Enterprises in order to gain the initiative in the industrial chain competition must be the integration of the industrial chain. For enterprises of the same type in the industrial chain, enterprises should enhance their concentration through horizontal integration and expand the scope of their market forces so as to increase their control over market prices and obtain monopoly profits. Enterprises can merge themselves with their own peers, competitors and other resources at the same production level through acquisitions, mergers and alliances to establish more effective operation systems. For upstream and downstream enterprises in the product supply chain, enterprises can integrate themselves Quasi-integration of the contract to its integration constraints, and ultimately to maximize the industrial profits; In addition, companies can also have a close contact with the company's business oblique integration.

\section{Conclusion}

Manufacturing services can be seen everywhere, but there is no specific path to change. This article analyzes how ShaanGu made its transition to service-oriented manufacturing, and provided some suggestions at the same time, which provided some references and operability paths for other enterprises. 


\section{Funding}

Shaanxi Soft Science Research Project (2017KRM064); Shaanxi Province Social Science Fund Project (2016R035); Xi'an Soft Science Project (2016044SF/RK07(2)); Xi'an Social Science Planning Fund Project (17J69).

\section{The Author}

Zhao Wu (1967-) is a native of Xi'an, Shaanxi Province. Currently, he is associate professor, doctoral tutor and master tutor in School of Economics and Management of Xidian University. His research interests include innovation and entrepreneurship and strategic management.

Liu Wei (1993-) is a native of Luliang in Shanxi province. She is a graduate student in School of Economics and Management of Xidian University. Her research interests include technical economics and management.

\section{References}

[1] Ren, G. and Gregory, M. (2007) Servitization in Manufacturing Companies. Paper Presented at 16th Frontiers in Service Conference, San Francisco.

[2] Gebauer, H., Gustafsson, A. and Witell, L. (2011) Competitive Advantage through Service Differentiation by Manufacturing Companies. Journal of Business Research, 64, 1270-1280. https://doi.org/10.1016/j.jbusres.2011.01.015

[3] Baines, T. and Lightfoot, H. (2013) Made to Serve: How Manufacturers Can Compete through Servitization and Product service Systems. John Wileyand Sons, Chichester.

[4] Fang, E., Palmatier, W.R. and Steenkamp, J.-B.E. (2008) Effect of Service Transition Strategy on Firm Value. Journal of Marketing, 72, 1-14.

https://doi.org/10.1509/jmkg.72.5.1

[5] Suarez, F.F., Cusumano, M.A. and Kahl, S.J. (2013) Services and the Business Models of Product Firms: An Empirical Analysis of the Software Industry. Management Science, 59, 420-435. https://doi.org/10.1287/mnsc.1120.1634

[6] Visnjic, I., Wiengarten, F. and Neely, A. (2016) Only the Brave: Product Innovation, Service Business Model Innovation, and Their Impact on Performance. Journal of Product Innovation Management, 33, 36-52. https://doi.org/10.1111/jpim.12254

[7] Sun, L.Y., Li, G. and Jiang, Z.B. (2007) 21st Century Advanced Manufacturing Model-Service-oriented Manufacturing. China Mechanical Engineering, 18, 2307-2312.

[8] He, Z., Sun, L.Y. and He, Z.Q. (2008) The Rise of Service-Oriented Manufacturing and Its Traditional Supply Chain System with the Difference. Soft Science, 22, 77-81.

[9] Lin, W.J., Jiang, Z.B., Li, N., et al. (2009) A Summary of Research on Service Manufacturing Theory. Journal of Industrial Engineering and Management, No. 12, 35-38. 